\title{
ANALISIS NILAI REAKTIVITAS BATANG KENDALI TERAS RSG-GAS SETELAH 30 TAHUN BEROPERASI
}

\author{
Pardi Pardi dan Purwadi Purwadi \\ Pusat Reactor Serba Guna, Batan \\ Kawasan Puspiptek GD 31 Tangerang Selatan 15310 Banten \\ Email:pardi@batan.go.id,purwadi14@batan.go.id
}

\begin{abstract}
ABSTRAK
ANALISIS NILAI REAKTIVITAS BATANG KENDALI TERAS RSG-GAS SETELAH 30 TAHUN BEROPERASI. Reaktor RSG-GAS telah beroperasi lebih dari 30 tahun untuk berbagai keperluan seperti produksi radioisotop dan penelitian dalam bidang nuklir, industri, kesehatan, bahan, dll. Dalam waktu itu, telah banyak komponen, sistem dan struktur reaktor yang telah menurun unjuk kerjanya sehingga perlu untuk diganti, antara lain penggantian sistem batang kendali. Setelah mengalami penggantian maka perlu dilakukan analisis sistem batang kendali teras RSG-GAS yang merupakan satu-satunya sistem kendali reaktor. Tujuan penelitian ini adalah untuk untuk menganalisis nilai reaktivitas batang kendali melalui perhitungan dan eksperimen. Perhitungan nilai reaktivitas batang kendali reaktor RSG-GAS dilakukan dengan metode difusi menggunakan program komputer WIMSD-5B dan Batan-3DIFF. Hasil analisis menunjukan bahwa batang kendali teras RSG-GAS masih layak digunakan untuk mengoperasikan reaktor. Nilai reaktivitas yang diperoleh tidak jauh berbeda dengan perbedaan rerata sekitar $10 \%$.
\end{abstract}

Kata kunci: reaktor RSG-GAS, nilai reaktivitas, batang kendali, komputer Batan-3DIFF .

\section{ABSTRACT}

ANALYSIS OF CONTROL RODS REACTIVITY WOTRH OF THE RSG-GAS CORE AFTER 30 YEARS OPERATION. The RSG-GAS reactor has been operating for more than 30 years for various purposes such as radioisotope production and researchs in the fields of nuclear, industry, health, materials etc. During that time period, performances of reactor components, systems and structures have decreased, which require replacements. After replacements, it is necessary to analyze the control rod system as the only one reactor control system. The purpose of this work is to analyze the reactivity worth of the control rod by calculations and experiments. The calculation is done by the diffusion method using the WIMSD-5B and Batan-3DIFF codes. The results of the analysis showed that the RSG-GAS core control rods were still suitable to be used to operate the reactor. The resulted reactivity value is not much different with the average difference of about $10 \%$.

Keywords: RSG-GAS reactor, reactivity worth, control rod, Batan-3DIFF code. 


\section{PENDAHULUAN}

RSG-GAS telah beroperasi lebih dari 30 tahun untuk tujuan produksi radioisotop dan penelitian dalam berbagai bidang seperti nuklir, industri, kesehatan material dan lain lain. RSG-GAS memiliki daya nominal 30 MW (termal) namun reratanya dioperasikan 15 MW dan menghasilkan fluks neutron termal dalam orde $1,2 \times 10^{14} \mathrm{n} / \mathrm{cm}^{2} \mathrm{~s}$ [1-2]. Pada teras setimbang menggunakan 40 bahan bakar dan 8 batang kendali, dikelilingi oleh elemen berilium dan blok berilium sebagai reflektor. Komponen-komponen teras reaktor disusun pada kisi-kisi yang terdiri atas 10 x 10 posisi. Reaktor menggunakan air ringan sebagai pendingin teras dan juga sebagai moderator. Elemen bakar yang digunakan jenis MTR dan terdiri dari 21 pelat elemen bakar. Setiap pelat elemen bakar terdiri atas rangka $\mathrm{AlMg} 2$ dan dua lembaran penutup dari bahan yang sama, yang membungkus pelat meat dispersi U3Si2-Al kerapatan 2,96 g/cc dengan pengkayaan $19,75 \%{ }^{235} \mathrm{U} \quad$ [3-5]. Elemen bakar kendali terdiri dari 15 pelat elemen bakar dan disisipi penyerap jenis-garpu (fork type). Perangkat penyerap terdiri atas dua bilah Ag-In-Cd yang diberi lapisan baja tahan karat [6].

\section{Reaktor RSG-GAS beroperasi} dengan rata-rata energi dibangkitkan sebesar 625 MWd dan setiap teras dilakukan pergantian bahan bakar dengan pola 5/1 [7-
9]. Pola $5 / 1$ berarti terdapat 5 buah elemen bakar standar dan 1 buah elemen bakar kendali dimasukkan di awal siklus ke teras. Hal ini dilakuakan sebagai ganti dari 5 buah elemen bakar standar dan 1 buah elemen kendali yang sudah mencapai nilai fraksi bakar maksimal. Setiap pergantian teras dihitung ulang nilai parameter neutronik reaktor untuk menjamin reaktor beroperasi dengan selamat. Pada operasi normal reaktor RSG-GAS dikendalikan oleh batang kendali yang terdiri dari 8 elemen kendali (EK) ang dikelompokkan menjadi 7 Bank Control Rods dan 1 Regulating Rod. Batang kendali harus dianalisis kemampuannya setelah reaktor beroperasi 30 tahun. Dari segi kemampuan pasti menurun oleh faktor usia, namun berapa berapa lama absorber batang akan diganti sesuai dengan kamampuannya. Analisis nilai reaktivitas batang kendali dilakukan berdasarkan hasil eksperimen yang akan dibandingkan dengan hasil perhitungan dengan menggunakan program komputer WIMSD/5B dan Batan-3DIFF [10-11]. Sebagai persyaratan operasi nilai reaktivitas batang kendali harus lebih besar 1,5 x reaktivitas lebih teras [12-13]. Jika nilai reaktivitas batang kendali hasil eksperimen tidak terpenuhi, diartikan bahwa absorber batang kendali sudah menunjukkan penurunan kemampuannya sehingga harus segera diganti.

Dalam desain reaktor RSG GAS dinyatakan bahwa batang kendali harus 
segera diganti setelah pengoperasian 40 siklus, dimana satu siklus operasi adalah 750 MWD [14]. Dalam analisis nilai reaktivitas batang kendali, ada beberapa hal penting yang perlu diperhatikan karena merupakan kriteria keselamatan operasi RSG-GAS, diantaranya adalah: stuck rod condition, fluks neutron, Fasilitas Iradiasi dan CIP. Oleh karena itu, makalah ini mempunyai tujuan untuk menentukan nilai reaktivitas batang kendali dan parameter operasi reaktor teras 97, 98 dan 99. Pengukuran parameter operasi reaktor dilakukan setelah reaktor kritis pada siklus awal teras, kemudian dilakukan eksperimen pemuatan reaktivitas lebih. Hasil pengukuran parameter operasi reaktor pada siklus awal teras (Beginning of Cycle = BOC) dibandingkan dengan hasil perhitungan. Perhitungan parameter operasi reaktor terhadap panjang siklus operasi reaktor dilakukan dengan Batan-2DIFF [1518].

\section{DISKRIPSI TERAS RSG-GAS}

RSG-GAS merupakan reaktor riset jenis MTR (Material Testing Reactor) pertama di dunia dengan menggunakan bahan bakar elemen bakar pengkayaan Uranium rendah, LEU (Low Enriched Uranium). Pada saat desain RSG-GAS dilaksanakan, hanya tersedia elemen bakar LEU jenis oksida (U3O8-Al) yang dapat digunakan untuk memenuhi spesifikasi yang ditentukan. Oleh karena itu RSG-GAS menggunakan bahan bakar oksida dengan densitas Uranium dalam meat sebesar 2,96 g/cc dengan pengkayaan ${ }^{235} \mathrm{U}$ sebesar 19,75\%. Dalam rangka meningkatkan kinerja reaktor, telah dilakukan konversi teras RSG GAS dari bahan bakar oksida menjadi silisida. Hal ini dilakukan karena penggunaan bahan bakar silisida dengan densitas Uranium yang lebih tinggi dapat meningkatkan panjang siklus operasi reaktor. Susunan teras setimbang (TWC) merupakan konfigurasi teras setimbang (TWC) silisida RSG-GAS. Teras aktif TWC (Typical Working Core) terdiri atas 40 elemen bakar standar (EB), 8 elemen bakar kendali (EK), satu posisi iradiasi di tengah (CIP) yang besar yang terdiri atas $2 \times 2$ posisi kisi teras, dan 4 posisi iradiasi (IP) di dalam teras reaktor, masing-masing mengambil satu posisi kisi teras. Sehingga keseluruhan teras TWC terdiri atas 960 pelat elemen bakar, yang berarti identik dengan 45,7 elemen bakar standar. Reaktivitas lebih teras setimbang awal RSG GAS merupakan kondisi penting dalam disain teras reaktor. Reaktivitas lebih teras setimbang awal RSG GAS merupakan pembatas dalam kaitannya dengan analisis terhadap kemampuan dari batang kendali untuk memadamkan reaktor.

Reaktor RSG-GAS mempunyai 4 buah Posisi Iradiasi Sentral (CIP) dan 2 buah Posisi Iradiasi (IP) pada teras. Selain itu didalam teras ada 5 fasilitas sistem rabbit, 
tujuh elemen reflektor berilium yang memiliki lubang berdiameter $50 \mathrm{~mm}$ dan dapat digunakan sebagai fasilitas iradiasi reflektor atau diisi dengan berilium bila tidak digunakan. Fasilitas iradiasi dalam teras reaktor digunakan untuk produksi radioisotop, batu topaz, serta analisis aktivasi neutron permintaan dari industri, lembaga litbang dan universitas [19-20]. Selain fasilitas iradiasi dalam teras, reaktor RSG-GAS mempunyai 6 tabung berkas neutron yang digunakan untuk penelitian dan fasilitas silicon doping serta fasilitas power ramp test facility (PRTF).

\section{METODOLOGI}

Peralatan yang digunakan adalah Reaktivitimeter, Servorgor 320 untuk pencatat reaktivitas, Detektor FC start up (JKT01), dan Detektor daya CIC (JKT04). Adapun tahapan kegiatan untuk mengetahui nilai reaktivitas adalah sebagai berikut:

\section{Pengukuran nilai reaktivitas batang kendali}

Setelah pembentukan konfigurasi teras dengan pemuatan bahan bakar baru ke teras RSG-GAS maka dilakukan pengukuran reaktivitas lebih, reaktivitas batang kendali dan kondisi stuck rod sebagai persyaratan keselamatan. Pengukuran reaktivitas batang kendali pada teras kerja reaktor riset RSGGAS setelah 30 tahun beroperasi perlu dilakukan. Hal ini berhubungan dengan kemampuan batang kendali untuk memadamkan reaktor dan memastikan kondisi stuck rod masih aman. Syarat yang diperlukan untuk pengukuran reaktivitas batang kendali ialah reaktor siap beroperasi pada daya rendah, dingin dan bersih, serta pada awal siklus setelah pemuatan teras. Reaktor dioperasikan pada daya rendah dan dilakukan pengukuran reaktivitas batang kendali dengan metode berpasangan satu satu. Nilai reaktivitas batang kendali yang diperoleh dari hasil pengukuran dengan metode kompensasi ini akan diperoleh nilai reaktivitas padam, reaktivitas total, reaktivitas lebih dan reaktivitas kondisi stuck rod dapat diketahui. Untuk mengetahui reaktivitas batang kendali yang lebih rinci pada setiap ketinggian posisi batang kendali, dilakukan dengan menggunakan program interpolasi linier [21]. Apabila terjadi perubahan reaktivitas akibat adanya gangguan teras, dengan melihat posisi batang kendali akan dapat diketahui reaktivitasnya. Selain itu data tersebut dapat pula digunakan untuk mengatur pengoperasian reaktor kembali setelah terjadinya scram (mati tiba-tiba) karena adanya pembangkitan xenon. Pengukuran reaktivitas batang kendali yang dilakukan setiap awal siklus teras baru (BOC=Beginning of Cycle), dimaksudkan untuk mengetahui harga reaktivitas masingmasing dari delapan batang kendali dan karakteristik reaktivitas terasnya. Data 
reaktivitas yang dihasilkan dari servorgor 320 sebagai posisi batang kendali disusun dalam sebuah tabel dan perhitungannya dilakukan dengan menjumlahkan setiap langkah perubahan reaktivitas mulai posisi 0 $\mathrm{cm}$ sampai dengan posisi $60 \mathrm{~cm}$. Selanjutnya dibuat kurva reaktivitas sebagai fungsi posisi pemasukan atau penarikan batang kendali yang dikenal dengan kurva S. Hasil eksperimen ini akan dibandingkan dengan hasil perhitungan dengan mennggunakan program WIMSD/5B dan Batan -3DIFF serta akan diprediksi kemampuan batang kendali berapa siklus lagi atau berapa lama lagi mampu untuk melakukan fungsinya memadamkan reaktor.

\section{Program Perhitungan WIMSD/5B dan Batan-3DIFF}

Paket program WIMS merupakan paket program yang digunakan dalam perhitungan sel dan menggenerasi konstanta kelompok difusi. Paket program WIMSD/5B merupakan penyempurnaan dari versi sebelumnya, yaitu WIMS/D4. Program WIMSD/5B menggunakan library atau konstanta mikroskopik yang terbaru yaitu ENDF-VII.1 [22] hanya bisa melakukan perhitungan transport neutron satu dimensi, sehingga dalam penggunaannya perlu dilakukan pemodelan sel teras. Pemodelan sel teras dilakukan untuk membuat konstanta kelompok makroskopik material teras. Nilai konstanta kelompok yang dihasilkan merupakan nilai konstanta kelompok rerata sel yang diperoleh dengan melakukan homogenisasi material sel [22]. Program perhitungan computer (code) Batan-2DIFF dan Batan-3DIFF adalah suatu program komputer yang dipergunakan untuk menyelesaikan persamaan difusi neutron dengan banyak kelompok energi dalam geometri 2D dan 3D. Akurasi perhitungan parameter teras reaktor RSG-GAS dengan Batan-2DIFF dan Batan-3DIFF ditentukan oleh tampang lintang material penyusun teras, pemodelan teras yang detail, dan keakuratan perhitungan fraksi bakar tiap elemen bakar dalam teras[25]. Validasi dan verifikasi penggunakan paket program WIMS/D5, Batan-2DIFF dan Batan-3DIFF sudah dilakukan oleh peneliti terdahulu [2324]. Batasan desain teras yang digunakan untuk menentukan parameter neutronik agar operasi reaktor tetap aman adalah [25]:

a) Reaktivitas lebih maksimum teras $10 \%$ $\Delta \mathrm{k} / \mathrm{k}$

b) Reaktivitas lebih pada saat BOC, dingin dan tanpa $\mathrm{Xe}<10,0 \% \Delta \mathrm{k} / \mathrm{k}$

c) Margin padam yang tersedia pada saat $\mathrm{BOC}$, dingin dan tanpa Xe harus lebih besar dari batas minimum sebesar $-0,5 \%$ $\Delta \mathrm{k} / \mathrm{k}$.

d) Reaktivitas pada saat EOC, panas dan Xe setimbang sekitar $1,7 \% \Delta \mathrm{k} / \mathrm{k}$.

e) Faktor puncak daya (ppf) radial maksimum 1,4

f) Reaktivitas target tunggal $<0,5 \% \Delta \mathrm{k} / \mathrm{k}$ 
g) Reaktivitas total untuk target $<2 \% \Delta \mathrm{k} / \mathrm{k}$

\section{HASIL DAN PEMBAHASAN}

Nilai reaktivitas batang kendali hasil pengukuran teras RSG-GAS ditunjukkan pada Tabel 1 untuk Teras 99, Tabel 2 untuk Teras 98 dan Tabel 3 untuk Teras 97. Dari hasil pengukuran kalibrasi batang kendali awal siklus (BOC) teras kerja dapat diketahui nilai neraca reaktivitas teras. Perhitungan reaktivitas lebih dengan konfigurasi bahan bakar tertentu dilakukan menggunakan paket program Batan-2DIFF. Reaktivitas batang kendali total hasil pengukuran untuk setiap teras dapat dilihat pada Tabel 2, hal tersebut terlihat ada perbedaan harga reaktivitas batang kendali total, reaktivitas lebih dan reaktivitas stuck rod dengan data desain. Reaktivitas total batang kendali pada Teras 99, 98 dan 97 bervariasi sekitar $13 \%$. Nilai reaktivitas batang kendali total antara perhitungan dan eksperimen tidak jauh berbeda hanya sekitar 4,5\% pada teras 99 dan $5 \%$ pada teras 98 serta $7,4 \%$ pada teras 97 . Dari ke 3 teras ini hasilnya cukup baik karena kurang dari $10 \%$ perbedaan antara pengukuran dan perhitungan. Reaktivitas stuck rod antara ke 3 teras juga memenuhi persyaratan. Batas keselamatan stuck rod masih diijinkan karena harga reaktivitas batang kendali masih mampu untuk mengontrol reaktivitas lebihnya dan pada kondisi stuck rod juga masih ada reaktivitas padamnya $-0,5 \%$ sesuai dengan nilai desainnya. Harga reaktivitas batang kendali berbeda untuk setiap teras.

Tabel 1. Reaktivitas batang kendali T-99

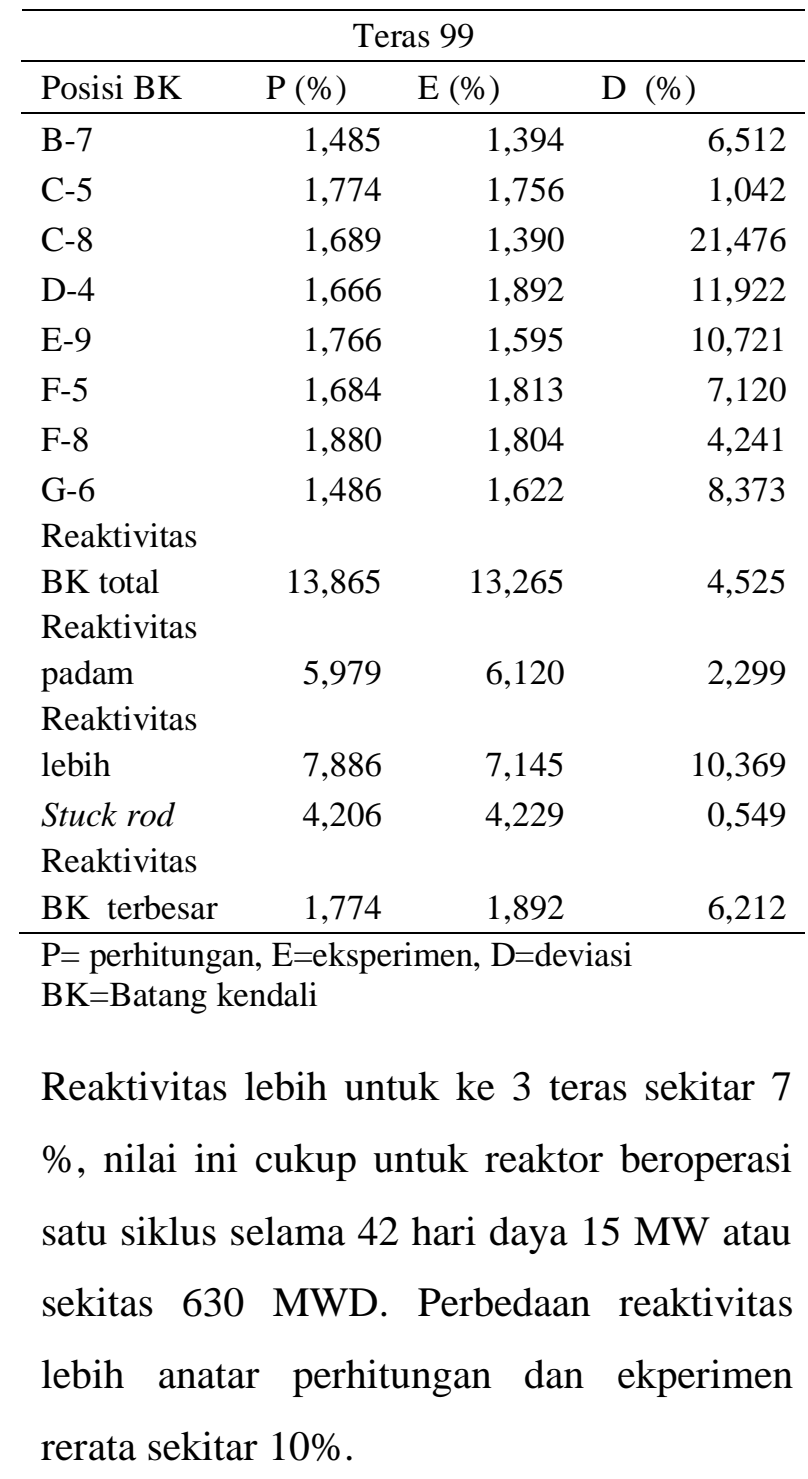


Tabel 2. Reaktivitas batang kendali T-98

\begin{tabular}{lrrr}
\hline \multicolumn{4}{c}{ Teras 98} \\
\hline Posisi BK & $\mathrm{P}(\%)$ & $\mathrm{E}(\%)$ & $\mathrm{D}(\%)$ \\
\hline B-7 & 1,486 & 1,377 & 7,894 \\
C-5 & 1,776 & 1,809 & 1,852 \\
C-8 & 1,693 & 1,408 & 20,240 \\
D-4 & 1,666 & 1,851 & 10,014 \\
E-9 & 1,769 & 1,570 & 12,679 \\
F-5 & 1,680 & 1,756 & 4,300 \\
F-8 & 1,882 & 1,817 & 3,583 \\
G-6 & 1,482 & 1,610 & 7,986 \\
Reaktivitas & & & \\
BK total & 13,866 & 13,198 & 5,056 \\
Reaktivitas & & & \\
padam & 5,992 & 6,197 & 3,308 \\
Reaktivitas & & & \\
lebih & 7,874 & 7,002 & 12,458 \\
Stuck rod & 4,109 & 4,345 & 5,424 \\
Reaktivitas & & & \\
BK terbesar & 1,882 & 1,851 & 1,658 \\
\hline
\end{tabular}

Reaktivitas padam yang ditunjukkan pada Tabel 1, 2 dan 3 juga bervariasi pada kisaran $6 \%$. Perbedaan perhitungan dan eksperimen pada ketiga teras tersebut sekitar $2-4 \%$. Reaktivitas batang kendali baik individu dan total serta reaktivitas padam dan stuck rod bernilai negatif sedangkan reaktivitas lebih bernilai positif. Salah satu contoh nilai reaktivitas batang kedali sebagai fungi posisi dapat dilihat pada Gambar 1 dan 2. Gambar 1 adalah harga reaktivitas batang kendali JDA01 s/d 04 dan Gambar 2 adalah harga reaktivitas batang kendali JDA05 s/d 08 untuk teras 97.
Tabel 3. Reaktivitas batang kendali T-97

\begin{tabular}{|c|c|c|c|}
\hline \multicolumn{4}{|c|}{ Teras 97} \\
\hline Posisi BK & $\mathrm{P}(\%)$ & $\mathrm{E}(\%)$ & $\mathrm{D}(\%)$ \\
\hline B-7 & 1,488 & 1,331 & 11,757 \\
\hline$C-5$ & 1,783 & 1,729 & 3,088 \\
\hline C-8 & 1,701 & 1,343 & 26,643 \\
\hline D-4 & 1,693 & 1,842 & 8,069 \\
\hline E-9 & 1,776 & 1,599 & 11,095 \\
\hline F-5 & 1,722 & 1,564 & 10,081 \\
\hline F-8 & 1,880 & 1,840 & 2,185 \\
\hline G-6 & 1,501 & 1,663 & 9,719 \\
\hline $\begin{array}{l}\text { Reaktivitas BK } \\
\text { total }\end{array}$ & 13,865 & 12,911 & 7,391 \\
\hline $\begin{array}{l}\text { Reaktivitas } \\
\text { padam } \\
\text { Reaktivitas }\end{array}$ & 6,018 & 5,810 & 3,584 \\
\hline lebih & 7,847 & 7,101 & 10,506 \\
\hline $\begin{array}{l}\text { stuck rod } \\
\text { Reaktivitas BK }\end{array}$ & 4,138 & 3,969 & 4,283 \\
\hline terbesar & 1,880 & 1,842 & 2,080 \\
\hline
\end{tabular}

Untuk teras 98 dan 99 adalah sama bentuknya sehingga diambil sebagai contoh saja teras 97. Perbedaan harga reaktivitas batang kendali ini dikarenakan konfigurasi teras berbeda dalam pengukuran. Artinya perbedaan nilai reaktivitas batang kendali ini disebabkan manajemen bahan bakar di dalam teras. Batang kendali mempunyai elemen penyerap yaitu AGInCd. Semakin lama di dalam teras juga berkurang daya serapnya terhadap neutron maka kemampuannya semakin berkurang juga. Menurut LAK (Laporan Analisis Keselamatan) elemen kendali diganti setelah akhir siklus ke 42 (T-42) jika reaktor dioperasikan setiap siklusnya 750 MWD. 


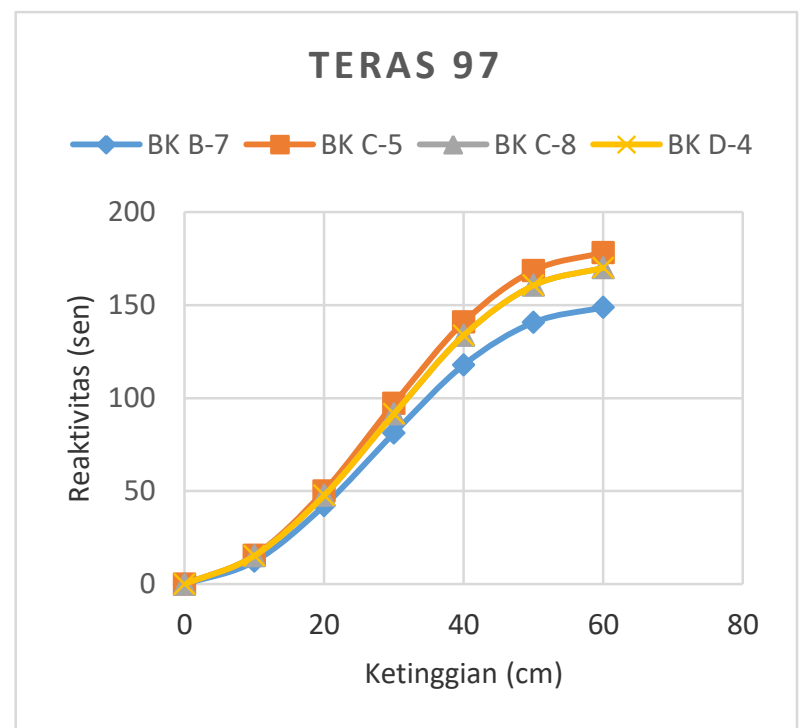

Gambar 1. Kurva batang kendali B-7, C-5, C-8 dan D-4

Elemen kendali diganti setelah reaktor beroperasi selama 31.500 MWD. Mulai dari teras pertama hingga teras ke 42 reaktor telah beroperasi selama 25.804,17 MWD. Penggantian elemen kendali telah dilakukan setelah reaktor beroperasi 31.500 MWD. Pergantian batang kendali dimulai pada teras 61.

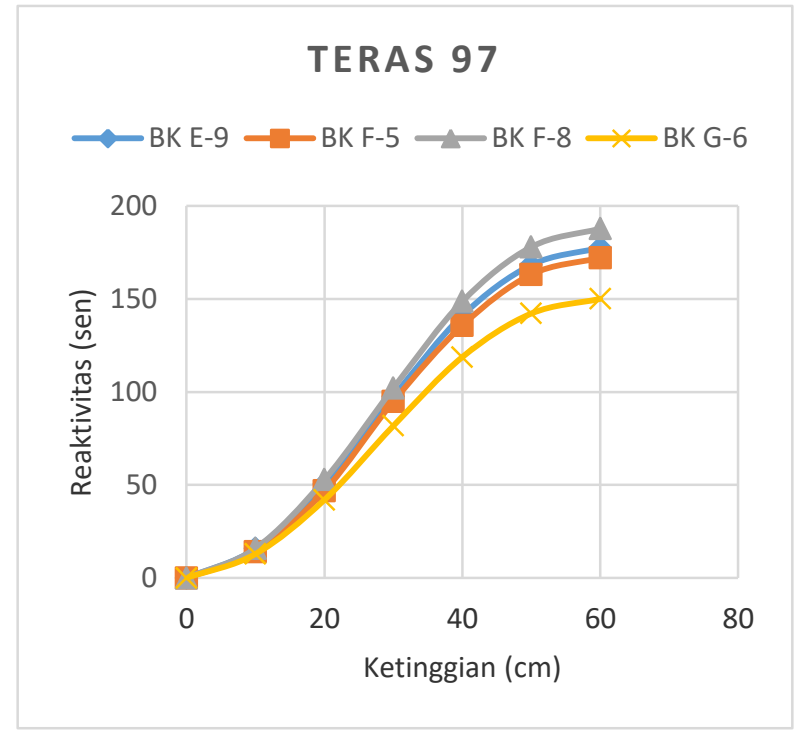

Gambar 2. Kurva batang kendali E-9, F-5, F-8 dan G-6
Besar kecilnya nilai reaktivitas padam ini sangat tergantung kepada kemampuan menyerap elemen absorber di dalam sistem batang kendali di teras. Diharapkan nilainya merata dan hampir sama ke 8 batang kendali yang ada di teras. Data pengukuran ditentukan berdasarkan penentuan reaktivitas pada posisi kritis reaktor bebas pengaruh sumber neutron pada awal siklus operasi. Untuk kondisi operasi daya tinggi, reaktivitas padam reaktor akan bertambah dikarenakan adanya penambahan reaktivitas xenon setimbang, dan reaktivitas padam ini akan bertambah seiring dengan bertambah lamanya operasi reaktor. Bila reaktor terpancung (scram) pada saat operasi daya tinggi, maka akan timbul pembangkitan xenon. Bila hal ini terjadi pada awal siklus, maka dalam waktu kurang dari dua jam, reaktor masih dapat dikritiskan kembali menuju daya semula, tetapi bila reaktor terpancung pada pertengahan atau akhir siklus, maka kemungkinan kecil untuk dapat mengkritiskan reaktor dalam waktu singkat, karena konsentrasi xenon dalam teras semakin bertambah. Pada kondisi ini reaktivitas padam mencapai harga maksimum, yaitu sama dengan reaktivitas total batang kendali. Waktu yang diperlukan untuk peluruhan konsentrasi xenon, agar reaktor dapat dikritiskan kembali yang disebut waktu padam reaktor.

Reaktivitas padam kondisi stuck rod dapat ditentukan dengan mengurangi harga 
reaktivitas padam dan reaktivitas batang kendali terbesar. Pada Tabel 1, 2 dan 3 ditunjukkan bahwa harga reaktivitas padam untuk teras kerja 99, 98 dan 97 RSG-GAS. Batas keselamatan menyatakan bahwa jika terjadi kondisi stuck rod dibutuhkan reaktivitas shut down margin - 0,5\%. Hal ini berarti untuk semua teras kerja terpenuhi, sehingga reaktor dapat dioperasikan karena reaktor masih dapat dipadamkan meskipun satu batang kendali gagal masuk.

Pada umumnya reaktivitas lebih cenderung menurun yang disebabkan oleh material pembentuk teras seperti elemen Berilium mengandung unsur litium disamping panas gamma yang tinggi. Namun dengan adanya harga reaktivitas lebih teras tersebut masih mampu untuk mengkritiskan reaktor selama satu siklus operasinya. Reaktivitas lebih teras yang didapat dari perhitungan dan eksperimen tidak jauh berbeda. Reaktivitas lebih diperlukan agar reaktor dapat dioperasikan sesuai dengan waktu yang diperlukan. Reaktivitas lebih merupakan pengurangan dari reaktivitas total batang kendali dan reaktivitas padam reaktor. Reaktivitas lebih tersebut akan berkurang seiring dengan bertambah waktu operasi reaktor dalam satu siklus. Bilamana reaktivitas lebih tidak memungkinkan untuk mencukupi kebutuhan operasi, maka reaktor dipadamkan untuk pembentukan teras baru berikutnya. Untuk teras reaktor RSG-GAS, reaktivitas yang diperlukan untuk keperluan operasi adalah 9,2\% agar dapat dioperasikan selama 25 hari operasi daya penuh (30 MW), yang setara dengan 750 MWD. Namun dalam perjalanannya reaktor ada saatnya tidak dioperasikan dengan 750 MWD sesuai dengan kebutuhannya. Tujuh 3. Tujuh persen reaktivitas lebih teras sudah cukup untuk dioperasikan selama 630 MWD sehingga manajemen bahan bakar teras kerja reaktor RSG-GAS efektif dan dilakukan berdasarkan kebutuhan iradiasi sampel di dalam maupun di luar teras.

\section{KESIMPULAN}

1. Berdasarkan manajemen bahan bakar teras kerja RSG-GAS dan hasil pengukuran reaktivitas batang kendali dengan metode kompensasi berpasangan diperoleh nilai kesetimbangan reaktivitas teras.

2. Parameter neutronik dan parameter teras lainnya tidak ada yang melanggar batas keselamatan.

3. Selama reaktor RSG-GAS beroperasi 30 tahun sejak awal dioperasikan tahun 1987, pengelolaan reaktivitas telah dilakukan dengan baik. Hal ini sangat mendukung keselamatan operasi reaktor sehingga reaktor dapat digunakan untuk keperluan riset dan iradiasi target.

4. Nilai reaktivitas batang kendali masih mampu untuk melalukan fungsinya dan 
dipredikasi 7 tahun ke depan atau sekitar 22 siklus lagi akan mampu melakukan fungsinya dan akan dilakukan penggantian absorber batang kendali setelah itu.

\section{DAFTAR PUSTAKA}

[1]. SUTRISNO, PURWADI, "Analisis Neutronik Dummy Aluminium di Teras Reaktor RSG- GAS", Seminar Nasional Sains dan Teknologi Nuklir 2017, Bandung, 14 November 2017.

[2]. T. SURBAKTI, S. PINEM, T. M. SEMBIRING, "Analisis Pengaruh Densitas Bahan Bakar Silisida Terhadap Parameter Kinetik Teras Reaktor RSG-GAS”, Jurnal Penelitian Fisika dan Aplikasinya. 2013; 3(1): 19-30.

[3]. Y. E. YUlinATO, M. IMRON, "Manajemen Pengoperasian Reaktor RSG-GAS”, Pros. Semin. Nas. Teknol. dan Apl. Reakt. Nukl. PRSG, 2013.

[4]. SUTRISNO, “Analisis Optimasi Target 235 U Pengkayaan Rendah (LEU) Untuk Mendukung Produksi 99 Mo Dan Target Batu Topaz di Reaktor RSG-GAS”, Ganendra, J. Iptek Nukl., vol. 21 No.1, pp. 25-35, 2018.

[5]. S. PINEM, T. M. SEMBIRING, P. H. LIEM, "Neutronic and ThermalHydraulic Safety Analysis for the
Optimization of the Uranium Foil Target in the RSG-GAS Reactor", Atom Indonesia, Vol. 42, no. 3, pp. 123-128, 2016.

[6]. S. PINEM, S. JATI, T. SURBAKTI, , T, M. SEMBIRING, "Optimization of Radioisotope Production at RSG-GAS Reactor Using Deterministic Method", Teknologi Indonesia, Vol. 35, pp. 3745, 2016.

[7]. T. M. SEMBIRING, T. SURBAKTI, S. PINEM, "Neutronic Design of Mixed Oxide-Silicide Cores for the Core Conversion of RSG-GAS Reactor", Atom Indonesia., Vol. 27, no. 2, pp. 85-1001, 2001.

[8]. P. H. LIEM, "Development and Verification of Batan's Standard, Two-Dimensional Multigroup Neutron Diffusion Code", Atom Indonesia., Vol. 20, no. 1, pp. 1-19, 1994.

[9]. S. PINEM, P. H. LIEM, T. M. SEMBIRING, T. SURBAKTI, "Fuel element burn-up measurements for the equilibrium LEU silicide RSG GAS (MPR-30) core under a new fuel management strategy", Ann. Nucl. Energy, vol. 98, 2016.

[10]. P. H. LIEM, “Validation of BATAN'S Standard 3-D Diffusion Code, BATAN-3DIFF, on the First Core of RSG GAS”, Atom Indonesia, vol. 25, no. 1 , pp. 47-53, 1999. 
[11]. WIMSD/5B, "Deterministic Multigroup Reactor Lattice Calculations, NEA-1507/04.” 2004.

[12]. P. H. LIEM, T. TARYO, T. M. SEMBIRING, S. HIROSHI, AND N. YOSHITAKA, "Study on the control rod interaction effect in RSG gas multipurpose reactor (MPR-30)", Ann. Nucl. Energy, vol. 29, no. 6, pp. 701716, 2002.

[13]. T. M. SEMBIRING, "Penggunaan Paket Program WIMSD/5B.12 dan BATAN-2DIFF untuk RSG-GAS," PRSG, April, 2011.

[14]. SETIYANTO, T. SURBAKTI, "Analysis of Gamma Heating at Triga Mark Reactor Core Bandung using Plate Type Fuel”, Jurnal Tri Dasa Mega. 2016; 18(3): 127-134

[15]. ROKHMADI, T. SURBAKTI, "Efek Densitas Bahan Bakar Terhadap Parameter Koefisien Reaktivitas Teras RRI”, Jurnal Tri Dasa Mega. 2013; 15(2): 77-89

[16]. L. SUPARLINA L, T. SURBAKTI, “Analisis Pola Manajemen Bahan Bakar Desain Teras Reaktor Riset Tipe MTR", Jurnal Tri Dasa Mega. 2014; 14(3): 89-99

[17]. BATAN. Laporan Analisis Keselamatan RSGGAS rev 10.1 . Batan; 2011.

[18]. T. SURBAKTI T, S. PINEM, T. M. SEMBIRING, L. SUPARLINA, J.
SUSILO, "Desain Konseptual Teras Reaktor Riset Inovatif Berbahan Bakar Uranium-molibdenum dari Aspek Neutronik", Jurnal Tri Dasa Mega. 2012; 3(14): 178-191.

[19]. T. M. SEMBIRING, P. H. LIEM, T. SURBAKTI, "Fuel management strategy for the compact core design of RSG GAS (MPR-30)", RRFM 2000: research reactor fuel management, Colmar, 19-21 March 2000, 158-162.

[20]. P. H. LIEM, T SURBAKTI, D HARTANTO, "Kinetics parameters evaluation on the first core of the RSG GAS (MPR-30) using continuous energy Monte Carlo method", Progress in Nuclear Energy 109, 196203

[21]. T SURBAKTI, P PURWADI, "Karakteristik reaktivitas teras kerja RSG-GAS selama 30 tahun beroperasi", Jurnal Penelitian Fisika dan Aplikasinya (JPFA) 7 (1), 13-26.

[22]. T SURBAKTI, M IMRON, "Fuel burn-up calculation for working core of the RSG-GAS research reactor at BATAN Serpong", Jurnal Penelitian Fisika dan Aplikasinya (JPFA) 7 (2), 89-101.

[23]. T SURBAKTI, S PINEM, T. M. SEMBIRING, A HAMZAH, K NABESHIMA, "Calculation of Control Rods Reactivity Worth of RSG-GAS First Core Using 
Deterministic and Monte Carlo

Methods", Atom Indonesia 45 (2), 69-

79. 2019

[24]. T SURBAKTI, P PURWADI, "Analysis of Neutronic Safety Parameters of the Multi-Purpose Reactor-Gerrit Augustinus Siwabessy (RSG-GAS) Research Reactor at Serpong”, Jurnal Penelitian Fisika dan Aplikasinya (JPFA) 9 (1), 78-91

[25]. T. SURBAKTI, T. M. SEMBIRING, “Analisis Neutronik Teras RSG-GAS Berbahan Bakar Silisida”, Indonesian Journal of Physics 12 (3), 61-67 